\title{
Preparation of Whey Syrup by Immobilized $\beta$-Galactosidase
}

\author{
Shaohui ZHANG, ${ }^{1}{\text { Kiyohisa } \text { IMADA }^{2} \text { and Tomio OHASHI }}^{1}$ \\ ${ }^{1}$ Faculty of Agriculture, ${ }^{2}$ Faculty of Engineering, Miyazaki University Miyazaki-shi, 889-21, Japan
}

Received June 6, 1997; Accepted October 4, 1997

\begin{abstract}
A pilot plant, with immobilized $\beta$-galactosidase (IMG) in a plug flow reactor, was established to prepare whey syrup from cheese whey. The effects of space velocity and lactose concentration on the initial rate of lactose hydrolysis (IRLH) and the operational temperature effect on the half-life and productivity of IMG were investigated. When the space velocity of whey was controlled at $0.6 l /(l \cdot \mathrm{min})$, consolidation and channeling did not occur in the pilot plant. A better IRLH was obtained when the whey had high lactose concentration. With an increase in operational temperature in the pilot plant, the IRLH was increased. However, the half-life of IMG was shortened, as a result, the productivity of IMG decreased. The best temperature was $10^{\circ} \mathrm{C}$ for the operation of the pilot plant. The plant could be operated for as long as 50 days at $10^{\circ} \mathrm{C}$ if the IMG is washed by sterilized deionized water for $1 \mathrm{~h}$ each day. When the IRLH decreases to 10\%, the IMG is treated by phosphate buffer solution (0.01 $\mathrm{M}, \mathrm{pH}$ 6.4) and tetramethylammonium chloride solution (0.03\%, pH 2.5$)$ for $30 \mathrm{~min}$, respectively. These results show that the developed pilot plant had prospects in the dairy industry because it could be operated continuously for a long period, the washing and sterilization were simple, and the rate of lactose hydrolysis (RLH) was more than $80 \%$ in the whey syrup.
\end{abstract}

Keywords: whey syrup, immobilized $\beta$-galactosidase, plug flow reactor

Whey, as a main by-product of cheese and casein manufacture, is usually discharged into rivers due to its lowsweetness, low solubility, and poor digestibility. It causes serious environmental pollution because of its high biological oxygen demand (Kosikowski, 1979; Yang \& Silva, 1995). On the other hand, the volume of whey is $90 \%$ of whole milk, it contains almost all the lactose, many whey proteins and a part of the minerals. Because the whey is not utilized, this leads to high production cost in the dairy industry (Zadow, 1984). To solve these problems, the lactose in whey can be hydrolyzed by $\beta$-galactosidase, such that the whey is changed to whey syrup with higher sweetness and solubility (Wierzbicki \& Kosikowski, 1972; Chiu \& Kosikowski, 1985). Therefore, the whey syrup can be used to make various products in the food industry, such as infant formula, yogurt, icecream, candy, bread, and beer (Pivarnik et al., 1995). Moreover, most recent studies suggest that many different kinds of oligosaccharides are formed during the lactose hydrolysis (Mozaffar et al, 1985; Toba, 1985; Prenosil et al., 1987). The whey syrup is also used as a functional food material with higher added value in the food industry.

As early as 1972, Wierzbicki and Kosikowski hydrolyzed lactose in skim milk and whey in a continuous-stirring tank reactor by polyacrylamide-entrapped $\beta$-galactosidase. With the development of biotechnology, the source, property, and application of enzymes have been increasingly studied during the last several years. However, continuous hydrolysis of lactose in milk or whey has not proved easy. Among the difficulties to be overcome are the following: milk or whey encourages microbial growth at the optimum temperature of the enzyme; milk protein tends to adsorb onto the immobi- lized enzyme surface and foul the reactor (Mahoney, 1985; Pivarnik et al. 1995). Furthermore, when the immobilized enzyme is plugged in a column, it is liable to cause channeling and consolidation (Bakken et al., 1990; Bodalo et al., 1995; Chen \& Zall, 1983). In this experiment, we designed a pilot plant with three stages of the reactor for the preparation of whey syrup and operated this system at low temperature to reduce the microbial contamination. Finally, the operational conditions of the pilot plant were explored.

\section{Materials and Methods}

Enzyme and whey In this experiment, the $\beta$-galactosidase was derived from Kluveromyces fragilis (Mahoney, 1985 ) and was immobilized by sodium alginate for a granule of $1 \mathrm{~mm}$. The activity of immobilized $\beta$-galactosidase (IMG) was 2100 lactose units per $1 \mathrm{~g}$. One lactose unit is defined as the amount of enzyme required to hydrolyze $1 \mu \mathrm{mol}$ of lactose in $1 \mathrm{~min}$ by the following measurements: two grams of IMG was placed into $100 \mathrm{ml}$ lactose solution (15\% lactose concentration, $\mathrm{pH} \mathrm{6.5)} \mathrm{and} \mathrm{incubated} \mathrm{for} 10 \mathrm{~min}$ at $45^{\circ} \mathrm{C}$; the remaining lactose concentration was then measured by high performance liquid chromatography (HPLC).

The whey was prepared from a demineralized whey powder (Doom Food Ingredients, Ltd., Beilen, Netherlands) which was composed of $56.04 \%$ lactose, $35.52 \%$ protein, $3.96 \%$ minerals, $1.70 \%$ fat, and $2.78 \%$ water. Two hundred eighty grams of whey powder per $1 l$ of deionized water was dissolved, and whey proteins were removed by acidifying with $\mathrm{HCl}$ until the $\mathrm{pH}$ reached 4.2 , followed by heating at $55^{\circ} \mathrm{C}$ for $5 \mathrm{~min}$ and then centrifuging at $7000 \times g$ for $5 \mathrm{~min}$. The composition of the obtained whey was $15.52 \%$ lactose, 
$0.56 \%$ protein, $0.81 \%$ minerals and $83.11 \%$ water. As a substrate, the above whey was adjusted back to $\mathrm{pH} 6.5$, and the lactose was diluted to the necessary concentration for further experiments.

Pilot plant The reactor made of stainless steel column $(150 \times 450 \mathrm{~mm})$ was divided into three stages of equal length and plugged with $8 l$ of IMG. The whey passed through the reactor from bottom to top and was circulated between reactor and tank by a pump, as shown in Fig. 1. The reaction temperature of the system was controlled by water circulation. Before the reaction, the air in the plug flow reactor was removed by a vacuum pump, and then the whey was inhaled into the reactor under low pressure conditions.

During the operation of the pilot plant, the IMG was washed with sterilized deionized water for $1 \mathrm{~h}$ and sterilized with phosphate buffer solution $(0.01 \mathrm{M}, \mathrm{pH} 6.4)$ and tetramethylammonium chloride solution $(0.03 \%, \mathrm{pH} 2.5)$, each for $30 \mathrm{~min}$. The washing was carried out each day, but the sterilizing was carried out according to the change in initial rate of lactose hydrolysis (IRLH) (Honda et al., 1991; Pastore et al., 1976).

Analysis and calculation The composition of the whey syrup were analyzed by a HPLC system which consisted of an LC-6AD pump, an RID-6A RI detector (Shimadzu, Ltd., Kyoto) and an Asahipak NH2P-50 column (4.6×250 mm, Showa Denko Co., Ltd., Tokyo). Lactose, glucose and galactose concentrations were determined from standard curves, and the oligosaccharide concentration was determined relative to the total saccharide concentration. The rate of lactose hydrolysis is the ratio of hydrolyzed lactose in whey at the end of processing and calculated as:

$$
\mathrm{RLH}(\%)=\frac{\mathrm{LC}_{\mathrm{b}}-\mathrm{LC}_{\mathrm{a}}}{\mathrm{LC}_{\mathrm{b}}} \times 100,
$$

where, RLH: rate of lactose hydrolysis, $\mathrm{LC}_{\mathrm{a}}$ : lactose concentration after reaction, $\mathrm{LC}_{\mathrm{b}}$ : lactose concentration before reaction.

IRLH is defined as the specific rate of lactose hydrolysis when the whey circulated through the reactor for the first time, which indicates the activity of the IMG in this experiment. During the run, the lactose concentrations were measured every day to calculate the RLH and IRLH. When the IRLH became half the original value, the IMG reached its half-life.

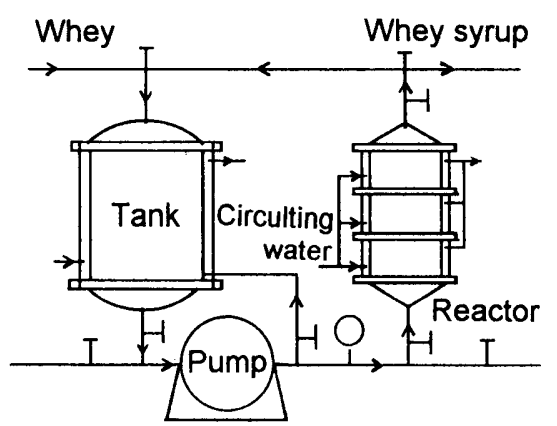

Fig. 1. Flow diagram for the preparation of whey syrup using immobilized $\beta$-galactosidase.
The productivity of IMG is the quantity of hydrolyzed lactose by $1 l$ of IMG in its half-life. It is calculated by:

$$
P=\frac{\sum_{i=1}^{t_{1 / 2}} \mathrm{RLH}_{i} \times Q \times C}{Y}
$$

where, $P$ : productivity of IMG $(\mathrm{kg} / l)$,

$Q$ : whey quantity $(l /$ day $)$,

$C$ : lactose concentration $(\mathrm{kg} / l)$,

$V$ : volume of IMG $(l)$,

$t_{1 / 2}:$ half-life of IMG (day),

RLH: rate of lactose hydrolysis (\%).

\section{Results and Discussion}

First, the effects of space velocity and lactose concentration on IRLH were studied at $25^{\circ} \mathrm{C}$ room temperature; the results are shown in Table 1.

The IRLH increased with increasing space velocity, and the highest IRLH was obtained at $0.6 l /(l \cdot \mathrm{min})$. The IRLH became lower when the space velocity was controlled at $0.8 \mathrm{l} /$ $(l \cdot \mathrm{min})$. This is due to the channeling which occurred, and most of the whey quickly passed through the reactor without reactions. When the space velocity was further increased, the whey was not able to pass through the reactor because consolidation occurred. In the plug flow reactor with liquid flow from bottom to top, the highest space velocity could be obtained when the product of the passage pressure and the sectional area of the reactor is equal to the weight of the immobilized enzyme (Bodalo et al., 1995). When the space velocity exceeded this level, the immobilized enzyme floated to the top of the reactor causing channeling. Further increases of space velocity led to consolidation. Thus, proper space velocity is very important to prevent channeling and consolidation in the plug flow reactor, and to ensure substrates feeding and products discharge. Consequently, the best space velocity was $0.6 l /(l \cdot \mathrm{min})$ for this size reactor.

On the other hand, the IRLH also increased with increasing lactose concentration. Carrara and Rubiolo (1996) suggested that the kinetics parameters were low when $\beta$ galactosidase was immobilized and the resulting reaction rate became lower. This is due to a diffusion layer existing between the granule of immobilized enzyme and the substrate, which restricted the movement of the substrate and product during the reaction. However, when the whey with $15 \%$ of lactose concentration flowed through the reactor in a space velocity of $0.6 l /(l \cdot \mathrm{min})$, the highest IRLH $(12.43 \%)$ was obtained in this experiment. This result suggests that the restriction could be eliminated by having a high lactose

Table 1. Effect of space velocity and lactose concentration on the IRLH $(\%) .^{a)}$

\begin{tabular}{ccccc}
\hline Lactose & \multicolumn{4}{c}{ Soace velocity $(l /(l \cdot \min ))$} \\
\cline { 2 - 5 } concentration (\%) & 0.2 & 0.4 & 0.6 & 0.8 \\
\hline 5 & 9.64 & 12.65 & 17.84 & 7.81 \\
10 & 14.25 & 16.81 & 20.16 & $-{ }^{b)}$ \\
15 & 16.09 & 18.47 & 21.43 & b) $^{b}$
\end{tabular}

a) IRLH: initial rate of lactose hydrolysis.

${ }^{b)}$ No data because channeling occurred. 
concentration and appropriate space velocity.

In order to study the effects of the operating temperature on the half-life and activity of IMG, the whey was circulated between reactor and tank in a space velocity of $0.6 \mathrm{l} /(\mathrm{l} \cdot \mathrm{min})$ at $5,10,20,30,40$ and $45^{\circ} \mathrm{C}$, respectively. The concentration of lactose in whey was the optimum substrate concentration of IMG (15\%), but it was the saturation lactose solubility at 5 and $10^{\circ} \mathrm{C}$, because the lactose solubility depends on the temperature. The IRLH and RLH were determined every day to calculate the half-life and productivity of IMG, and the results are shown in Table 2.

The IRLH increased with the operating temperature, but the half-life of IMG declined. The highest IRLH was $28.86 \%$ which was obtained at the optimum temperature of $45^{\circ} \mathrm{C}$. The IRLH exhibited little change between 30 and $45^{\circ} \mathrm{C}$. At $5^{\circ} \mathrm{C}$, the IRLH was $4.01 \%$ and increased to $16.34 \%$ at $10^{\circ} \mathrm{C}$. According to the enzyme reaction rate equation (MichaelisMenten equation), the reaction rate parameter varied significantly with changes in the reaction temperature and resulted in a geometric progressive change in the reaction rate. However, the IRLH did not significantly increase with the operating temperature increase. This might be due to the immobilization of the enzyme. When the enzyme was immobilized, a large change occurred in the structure of the enzyme protein (Zeffren \& Hall, 1993). Therefore, further work is necessary to elucidate this outcome.

Table 2. Effect of operating temperatures on the activity, half-life and productivity of IMG. ${ }^{a)}$

\begin{tabular}{lcccccc}
\hline \multirow{2}{*}{ Item } & \multicolumn{6}{c}{ Temperature $\left({ }^{\circ} \mathrm{C}\right)$} \\
\cline { 2 - 7 } & 5 & 10 & 20 & 30 & 40 & 45 \\
\hline Lactose & 11 & 13 & 15 & 15 & 15 & 15 \\
$\quad$ concentration $(\%)^{b)}$ & & & & & & \\
IRLH $(\%)^{c)}$ & 4.01 & 16.43 & 20.16 & 25.71 & 27.08 & 28.86 \\
Half-life (day) & 41 & 29 & 9 & 2.5 & 2.5 & 1 \\
Productivity $(\mathrm{kg} / l)$ & 16.62 & 41.80 & 13.23 & 5.98 & 6.36 & 2.6 \\
\hline
\end{tabular}

a)IMG: immobilized $\beta$-galactosidase.

${ }^{b)}$ Lactose concentration is its saturation solubility at 5 and $10^{\circ} \mathrm{C}$, and it is the optimum substrate concentration of IMG at other temperatures.

c)IRLH is the initial rate of lactose hydrolysis which indicates the activity of IMG.
The half-life of IMG changed quickly from 1 day to 41 days as the operation temperature varied from 45 to $5^{\circ} \mathrm{C}$. According to the results of Pastore et al. (1976), the microbial contamination is unavoidable when the milk and milk products are processed by IMG, and it rapidly increases as the temperature increases. When the temperature was between 30 and $40^{\circ} \mathrm{C}$, the lactic acid bacteria grew quickly, and this growth reduced the activity of the enzyme and shortened its half-life.

As the operating temperature increased, the half-life of IMG decreased and the productivity of IMG declined. The highest productivity of IMG was $41.80 \mathrm{~kg} / \mathrm{l}$ obtained at $10^{\circ} \mathrm{C}$. This may be due to the reduction in microbial contamination and the raising of the half-life. At $5^{\circ} \mathrm{C}$, the half-life was the longest, but the IRLH and the lactose solubility were low; so its productivity was lower compared to that at $10^{\circ} \mathrm{C}$. The productivity was found to depend mainly on IRLH and half-life.

Based on the previous results, the pilot plant was operated at $10^{\circ} \mathrm{C}$. The whey with $13 \%$ lactose concentration was circulated between reactor and tank in a space velocity of 0.6 $l /(l \cdot \mathrm{min})$. The effects of circulating times on RLH and the composition of the whey syrup were investigated, and the results are shown in Table 3.

The RLH increased with circulating times, after 6 times of circulation, almost all the lactose in the whey was hydrolyzed,

Table 3. Effect of circulating times on the $\mathrm{RLH}^{\alpha)}$ and composition of whey syrup.

\begin{tabular}{cccccc}
\hline \multirow{2}{*}{$\begin{array}{c}\text { Circulating } \\
\text { (times) }\end{array}$} & $\begin{array}{c}\text { RLH } \\
(\boldsymbol{\%})\end{array}$ & \multicolumn{4}{c}{ Saccharide concentration (\%) } \\
\cline { 3 - 6 } & 11.08 & 11.56 & 0.70 & 0.42 & 0.32 \\
\hline 1 & 35.77 & 8.35 & 2.23 & 1.36 & 1.06 \\
2 & 58.23 & 5.43 & 3.72 & 2.13 & 1.72 \\
3 & 67.69 & 4.20 & 4.33 & 2.56 & 1.91 \\
4 & 74.46 & 3.32 & 4.71 & 3.73 & 1.24 \\
5 & 80.15 & 2.58 & 5.11 & 4.36 & 0.95 \\
6 & 84.00 & 2.08 & 5.35 & 4.79 & 0.78 \\
7 & 85.77 & 1.85 & 5.48 & 5.02 & 0.65 \\
8 & & &
\end{tabular}

${ }^{a)} \mathrm{RLH}$ : rate of lactose hydrolysis.

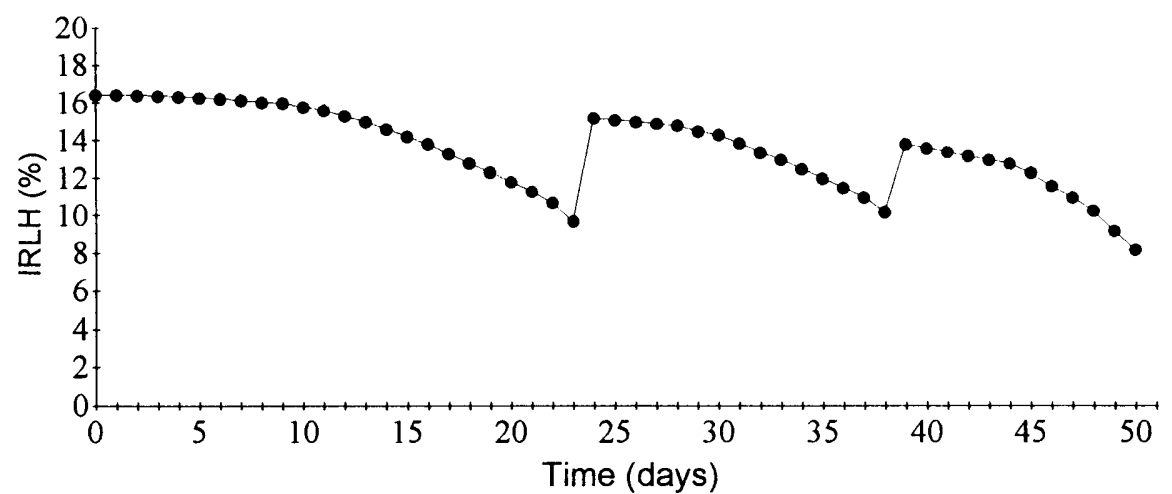

Fig. 2. Changes in IRLH with operating time. IRLH (initial rate of lactose hydrolysis) is the specific rate of lactose hydrolysis which indicates the activity of the immobilized $\beta$-galactosidase. The immobilized $\beta$-galactosidase was treated with phosphate buffer solution $(0.01 \mathrm{M}, \mathrm{pH} 6.4)$ and tetramethylammonium chloride solution $(0.03 \%, \mathrm{pH} 2.5)$ on $23 \mathrm{rd}$ and 38 th day. 
and the RLH was more than $80 \%$. These results suggest that the whey with high lactose concentration is an ideal substrate for enzyme processing, and whey syrup with high RLH can be obtained by this system.

The changes in saccharide concentrations in the whey syrup with circulating times were different. Glucose and galactose concentration increased with the hydrolysis of lactose. Furthermore, galactose concentration was always lower than the glucose concentration during the reaction. Thus, it shows that the oligosaccharides were mainly formed by the galactose with lactose hydrolysis. The oligosaccharide concentration increased up to 4 times of circulating, and about $16 \%$ of the total saccharides had turned into oligosaccharides, but afterward it decreased. This result suggests that the produced oligosaccharides were hydrolyzed by IMG as the circulating times continuously increased. Therefore, in order to produce a functional food material with higher added value, the circulating should be stopped before the decrease in oligosaccharide concentration.

Finally, in order to operate the pilot plant for a long time, the changes in IRLH with time and the time needed to treat IMG were investigated; the results are shown in Fig. 2. The IRLH decreased with time and became half the original value after $29 \mathrm{~d}$ (the half-life of IMG) at $10^{\circ} \mathrm{C}$, as shown in Table 2. In this case, we treated IMG using phosphate buffer solution and tetramethyl-ammonium chloride solution. As a result, it brought the IRLH back only to $75 \%$ of the original value and was not as good as expected. If this work was carried out when the IRLH decreased to about $10 \%$, it brought the IRLH back to $91 \%$ of the original value, as shown in Fig. 2. Based on this result, when we treated IMG on the 23rd and 38th day, respectively, the activity of IMG was recovered well and the pilot plant ran steadily for as long as 50 days.

Previous studies have indicated that the activity of $\beta$ galactosidase was inhibited by various ions and proteins in milk (Mahoney \& Adamchuk, 1980) and that the microorganism harms the activity of the enzyme during the reaction (Mahoney, 1985). Therefore, the IMG has to be washed and sterilized to maintain its activity during use. Honda et al (1991) washed the IMG with phosphate buffer solution at $\mathrm{pH}$ 7.1 and indicated that the amount of protein attached to IMG was under $22 \mu \mathrm{g} / \mathrm{mg}$ (dry IMG). Pastore et al. (1976) found the quaternary ammonium salt to be very effective in preventing bacterial contamination. The results in this experiment also proved that the phosphate buffer solution and quaternary ammonium salt were very effective for IMG in regenerating activity.

\section{References}

Bakken, A.P., Hill, C.G. and Amundson, C.H. (1990). Use of novel immobilized $\beta$-Galactosidase reactor to hydrolyze the lactose constituent of skim milk. Biotechnol. Bioeng., 36, 293-298.

Bodalo, A., Gomez, J.L.. Bastida, J. and Maximo, M.F. (1995). Fluidized bed reactors operating with immobilized enzyme systemdesign model and its experimental verification. Enzyme Microb. Technol., 17, 915-922.

Carrara, C.R. and Rubiolo, A.C. (1996). Determination of kinetics parameters for free and immobilized $\beta$-galactosidase. Process Biochem., 31, 243-248.

Chen, H.C. and Zall, R.R. (1983). Continuous lactose hydrolysis in fixed-bed and expanded-bed reactors containing catalytic resins. $J$. Food Sci., 48, 1741-1744.

Chiu, C.P. and Kosikowski, F.V. (1985). Hydrolyzed lactose syrup from concentrated sweet whey permeate. J. Dairy Sci., 68, 16-21.

Honda, H., Hashiba, H., Ahiko, K. and Takahashi, H. (1991). Methods for washing fibrous immobilized $\beta$-Galactosidase. Nippon Shokuhin Kogyo Gakkaishi, 38, 620-625 (in Japanese).

Kosikowski, F.V. (1979). Whey utilization and whey products. J. Dairy Sci, 62, 1149-1162.

Mahoney, R.R. and Adamchuk, C. (1980). Effect of milk constituents on the hydrolysis of lactose by lactase from Kluyveromyces fragilis. J. Food Sci., 45, 962-964.

Mahoney, R.R. (1985). Modification of lactose and lactose-containing dairy products with beta-galactosidase. In "Developments in Dairy Chemistry: Lactose and Minor Constituents," ed. by P.F. Fox. Elsevier applied science publishers, London and New York, pp. 8889.

Mozaffar, Z., Nakanishi K., and Matsuno, R. (1985). Formation of oligosaccharides during hydrolysis lactose in milk using $\beta$-galactosidase from Bacillus circulans. J. Food Sci., 50, 1602-1608.

Pastore, M., Morisi, F. and Leali, L. (1976). Reduction of lactose of milk by entrapped $\beta$-galactosidase IV. Results of long-term experiments on pilot plant. Milchwissenschaft, 31, 362-365.

Pivarnik, L.F., Senecal, A.G. and Rand, A.G. (1995). Hydrolytic and transgalactosylic activities of commercial $\beta$-galactosidase (lactase) in food processing. In "Advances in Food Nutrition Research vol. 38." ed. by Kinsella J.E. and Taylor S.L. Academic. San Diego, California. pp. 1-90.

Prenosil, J.E., Stuker, E. and Bourne, J.R. (1987a). Formation of oligosaccharides during enzymatic hydrolysis of lactose, part 1: state of the art. Biotechnol. Bioeng., 30, 1019-1025.

Prenosil, J.E., Stuker, E. and Bourne, J.R. (1987b). Formation of oligosaccharides during enzymatic hydrolysis of lactose, part 2 experimental. Biotechnol. Bioeng., 30, 1026-1031.

Toba, T. (1985). $\beta$-galactosidase - Its application to lactose hydrolysis and galactooligo-saccharide production. Jpn. J. Dairy Food Sci, 34. Al70-175.

Wierzbicki, L.E. and Kosikowski, S. (1972a). Food syrup from acid whey treated with $\beta$-galactosidase from $A$. niger. J. Dairy Sci, $\mathbf{5 6}$, 1182-1184

Wierzbicki, L.E. and Kosikowski, S. (1972b). Kinetics of lactose hydrolysis in acid whey by $\beta$-galactosidase from $A$. niger. J. Dairy Sci., 56, 1396-1399.

Yang, S.T. and Silva, E.M. (1995). Novel products and new technologies for use of a familiar carbohydrate, milk lactose. J. Dairy Sci. 78, 2541-2562.

Zadow, J.G. (1984). Lactose: properties and uses. J. Dairy Sci, 67, 2654-2660

Zeffren, E. and Hall, P.L. (1993). "The Study of Enzyme Mechanisms," 5th Ed., John Wiley and Sons, Inc., New York, pp. 60-69. 